\title{
Dipyridamole stress echo - the next step in evolution of stress imaging in the Echocardiography Laboratory at the Čakovec County Hospital
}

\section{(D)Mihajlo Kovačić* \\ (D)Marko Hranilović,}

Čakovec County Hospital, Čakovec, Croatia

\begin{abstract}
KEYWORDS: stress echocardiography, dipyridamole, dobutamine, coronary artery disease. CITATION: Cardiol Croat. 2019;14(3-4):109-110. | https://doi.org/10.15836/ccar2019.109
\end{abstract}

*ADDRESS FOR CORRESPONDENCE: Mihajlo Kovačić, Županijska bolnica Čakovec, I.G.Kovačića 1E, HR-40000 Čakovec, Croatia. / Phone: +385-98-266-774 / E-mail: mihajlo1983@gmail.com

ORCID: Mihajlo Kovačić, https://orcid.org/0000-0002-2577-9474 • Marko Hranilović, https://orcid.org/0000-0001-6522-5882

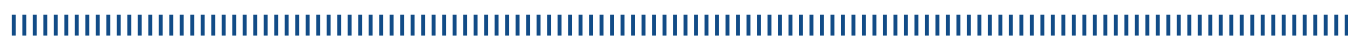

Introduction: Stress echocardiography is the combination of 2D echocardiography with physical, pharmacological or electrical stress. The diagnostic endpoint of the detection of myocardial ischemia is the induction of a transient change in regional function during stress. ${ }^{1}$ Myocardial ischemia results in a typical "cascade" of events in which the various markers are hierarchically ranked in a well-defined time sequence. Flow heterogeneity between subendocardial and subepicardial perfusion is the forerunner of ischemia, followed by metabolic changes, alteration in regional mechanical function, and only at a later stage by electrocardiographic (ECG) changes, global left ventricular dysfunction (LV) and pain. ${ }^{2}$ Wall motion and perfusion or coronary flow reserve (CFR) changes are highly accurate, and more accurate than ECG changes for detection and location of underlying coronary artery disease. However, wall motion is more specific and requires ischemia perfusion changes are more sensitive and may occur in the absence of true ischemia (microvascular disease, or LV hypertrophy). ${ }^{1}$ The three most common ischemic stressor are exercise, dobutamine, and vasodilators (dipyridamole, adenosine). They are equally potent for inducing wall abnormalities in the presence of a critical epicardial coronary artery stenosis. Dobutamine and exercise manly act through increased myocardial oxygen demand. Vasodilators act by stimulating A2 adenosinergic receptors present on the endothelial and smooth muscle cells of coronary arterioles and induce ischemia due to reduced subendocardial flow supply subsequent to inappropriate arteriolar vasodilatation and steal phenomena. ${ }^{1}$ Dipyridamole was the first pharmacological stress agent used for the diagnosis of coronary artery disease, with a pioneering indication proposed in Europe for the identification of ischemia during 12-lead ECG ${ }^{3}$, and later in the USA by Lance Gould as hyperemic stress perfusion imaging. ${ }^{4}$ Dipyridamole stress echocardiography pioneered in the year of 1985 (Picano et al). The safety record of high dose dipyridamole is well established on the basis of large scale multicentric studies with data from thousands of patients. The incidence of major complications, i.e. myocardial infarction, atrioventricular block, cardiac asystole, sustained ventricular tachycardia, is about $1 / 1500$ cases. The mortality rate is about 1/10000 cases, similar to that of the exercise stress test. Dipyridamole has a better safety profile than when stress testing with dobutamine, where the incidence of major adverse reactions is about 1/300 studies. ${ }^{5}$ Many centers from 1988 until today, have used high doses ad-

FIGURE 1. Dipyridamole stress echo timeline.
RECEIVED:

February 28, 2019

ACCEPTED:

March 24, 2019

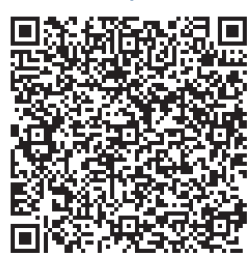

ministered in a short time (syringe-based infusion of $0.84 \mathrm{mg} / \mathrm{kg}$ ). Later, some studies were reproduced with these doses, and today, most centers worldwide use high dose delivered in 4-6 min. ${ }^{6}$

Center experience: In 2017 we started to perform stress echocardiography in Čakovec County Hospital. The first method was exercise echocardiography using treadmill protocol, with imperative do accomplish postexercise imaging as soon as possible ( $<1 \mathrm{~min}$ from the cessation of exercise) where patient moved immediately from treadmill to imaging bed. With this method we have information from exercise stress testing combined with echocardiographic wall motions analysis to make final interpretation. The second method and most used until recently in our echo lab is standard dobutamine stress protocol, starting with $5 \mathrm{ug} / \mathrm{kg} / \mathrm{min}$ and increasing $10,20,30$ and $40 \mathrm{ug} / \mathrm{kg} / \mathrm{min}$. If no endpoint is reached, atropine, usually in dose $0.25 \mathrm{mg}$, is added to maximal dobutamine dose infusion. We are using this method for coronary disease detection, but also low dose protocol, to asses myocardial viability, valvular pathology (low-flow aortic stenosis) and other indications. 


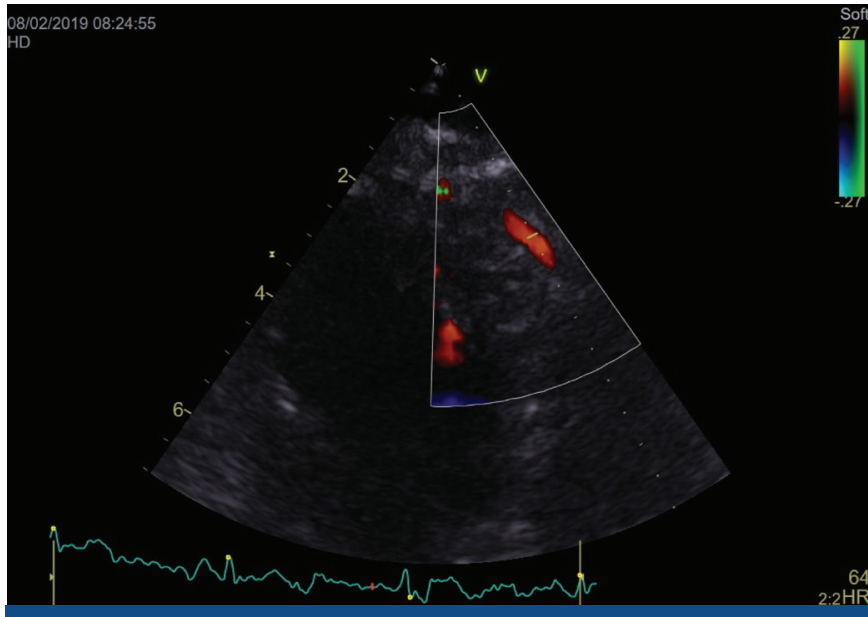

FIGURE 2. Distal left anterior descending artery - color doppler.

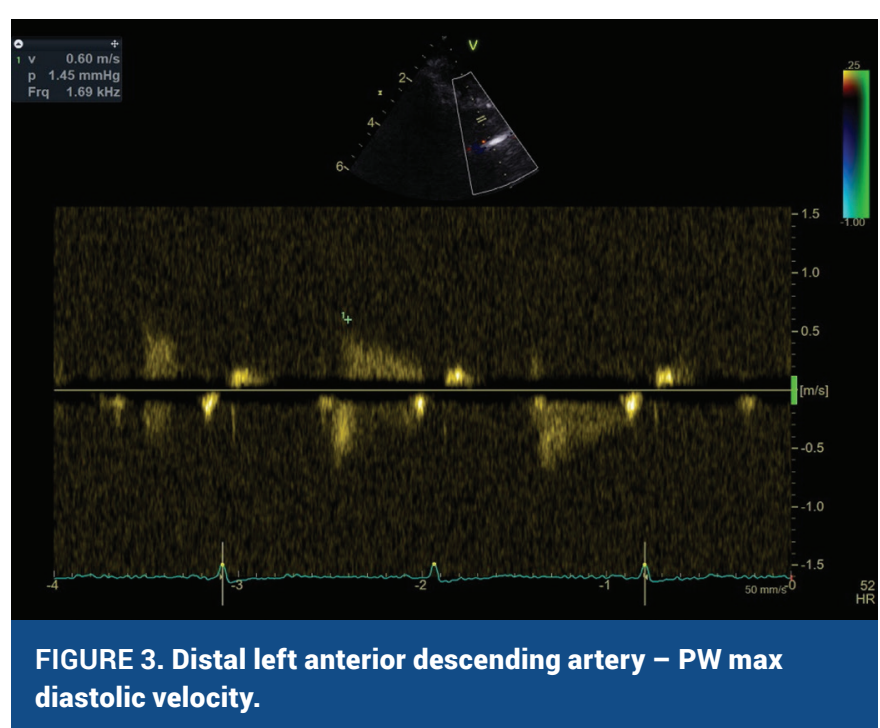

FIGURE 3. Distal left anterior descending artery - PW max diastolic velocity.

Recently we started vasodilator stress echocardiography using dipyridamole, and until today, we performed a test on 15 patients. Protocol diagram is showed in Figure 1. The dipyridamole dose employed for stress testing was $0.84 \mathrm{mg} / \mathrm{kg}$ administered in short time (syringe-based infusion at a rate of $0.21 \mathrm{mg} / \mathrm{kg} / \mathrm{min}$ during 4 minutes). A fast protocol is embraced because is known that high dose protocols in short time causes a three- to fourfold increase in coronary blood flow in normals and give best sensitivity and specificity for coronary pathology detection? ${ }^{7}$ Peak vasodilatation occurs 1 to 2 minutes after the end of infusion and the dipyridamole elimination half-time is 40 minutes which enables us enough time for imaging in the period of maximum stress. After image completion we give the antidote aminophylline (blocks adenosine receptors) even in negative cases. The antidote can also be used for emergent reversal of adverse dipyridamole-related events which we have not encountered in this limited series of tests. If technically feasible due to image quality, we perform measurement of coronary flow reserve in mid to distal left anterior descending artery (LAD) using pulse doppler (Figure $\mathbf{2}$ and Figure 3) before and after vasodilatation. CFR in many cases adds additional diagnostic value when combined with conventional wall motion analysis. Another tool to increase diagnostic accuracy, especially when image quality is impaired, are contrast agents (i.e. Optison) which help to delineate endocardial borders. All caffeine-containing foods (coffee, tea, chocolate, bananas, cola drinks) should be avoided for 12 hours before test and all theophylline-containing drugs (aminophylline) should be discontinued for at least 24 hours before test. Very low dose protocols can be used $(0.28 \mathrm{ug} / \mathrm{kg})$ to identify myocardial viability and have high specificity (higher than dobutamine) but lower sensitivity ${ }^{8}$. Absolute contraindications for dipyridamole stress test are active bronchospasm, 2nd or 3rd degree AV block and systolic blood pressure $<90$ $\mathrm{mmHg}$. Relative contraindications are methylxanthine use and remote history of restrictive airway disease.

Conclusion: Dipyridamole stress echocardiography can be used as a preferred stress test for the detection of coronary artery disease in patients unable to exercise and with contraindications to dobutamine (tachyarrhythmias, uncontrolled blood pressure). It is technically easier than exercise or dobutamine stress tests since image quality is less degraded by tachycardia, hyperventilation and hypercontractility. The test is equally accurate in comparison with dobutamine, but technically easier and safer ${ }^{9}$. In the future, dipyridamole test is planned to be the default method for pharmacological stress in our laboratory supported with contrast agents when necessary. Contrast perfusion stress echocardiography is the next planned step in years to come.

LITERATURE IIIIIIIIIIIIIIIIIIIIIIIIIIIIIIIIIIIIIIIIIIIIIIIIIIIIIIIIIIIIIIIIIIIIIIIIIIIIIIIIIIIIIIIIIIIIIIIIIIIIIIIIIIIIIIIIIIIIIIIIIIIIIIIIIIIIIIIIIIII

1. Sicari R, Nihoyannopoulos P, Evangelista A, Kasprzak J, Lancellotti P, Poldermans D, et al; European Association of Echocardiography. Stress echocardiography expert consensus statement: European Association of Echocardiography (EAE) (a registered branch of the ESC). Eur J Echocardiogr. 2008 Jul;9(4):415-37. https://doi.org/10.1093/ejechocard/jen175

2. Picano E. Dipyridamole-echocardiography test: historical background and physiologic basis. Eur Heart J. 1989 Apr;10(4):365-76. https://doi.org/10.1093/oxfordjournals.eurheartj.a059494

3. Tauchert M, Behrenbeck DW, Hötzel J, Hilger HH. [A new pharmacological test for diagnosing coronary artery disease (author's trans)]. Dtsch Med Wochenschr. 1976 Jan 9;101(2):35-7. https://doi.org/10.1055/s-0028-1104029

4. Gould KL, Westcott RJ, Albro PC, Hamilton GW. Noninvasive assessment of coronary stenoses by myocardial imaging during pharmacologic coronary vasodilatation. II. Clinical methodology and feasibility. Am J Cardiol. 1978 Feb;41(2):279-87. https://doi.org/10.1016/0002-9149(78)90166-2

5. Lette J, Tatum JL, Fraser S, Miller DD, Waters DD, Heller G, et al. Safety of dipyridamole testing in 73,806 patients: the Multicenter Dipyridamole Safety Study. J Nucl Cardiol. 1995 JanFeb;2(1):3-17. https://doi.org/10.1016/S1071-3581(05)80003-0

6. Lipiec P, Wejner-Mik P, Krzemińska-Pakula M, Kuśmierek J, Plachcińska A, Szumiński R, et al. Detection of single-vessel coronary artery disease by dipyridamole stress echocardiography: no longer a problem? Clin Physiol Funct Imaging. 2009 Apr;29(2):151-7. https://doi.org/10.1111/j.1475-097X.2008.00849.x

7. Dal Porto R, Faletra F, Picano E, Pirelli S, Moreo A, Varga A. Safety, feasibility, and diagnostic accuracy of accelerated high-dose dipyridamole stress echocardiography. Am J Cardiol. 2001 Mar 1;87(5):520-4. https://doi.org/10.1016/S0002-9149(00)01424-7

8. Varga A, Ostojic M, Djordjevic-Dikic A, Sicari R, Pingitore A, Nedeljkovic I, et al. Infra-low dose dipyridamole test. A novel dose regimen for selective assessment of myocardial viability by vasodilator stress echocardiography. Eur Heart J. 1996 Apr;17(4):629-34. https://doi.org/10.1093/oxfordjournals.eurheartj.a014918

9. Beleslin BD, Ostojic M, Stepanovic J, Djordjevic-Dikic A, Stojkovic S, Nedeljkovic M, et al. Stress echocardiography in the detection of myocardial ischemia. Head-to-head comparison of exercise, dobutamine, and dipyridamole tests. Circulation. 1994 Sep;90(3):1168-76. https://doi.org/10.1161/01.CIR.90.3.1168

10. hrvatski dvogodišnji ehokardiografski kongres s međunarodnim sudjelovanjem $10^{\text {th }}$ Croatian Biennial Echocardiography Congress with International Participation Poreč, 16. do 18.5.2019. 